\title{
The Teaching Practice and Study of the General Education Course "Wuhan Dialect and Culture"
}

\author{
Chong GUO ${ }^{1, a}$, Yu-Qin XIAO, \\ ${ }^{1,2}$ Wuhan Business University, No. 816, Dongfeng Ave. Wuhan, Hubei, China \\ aguochong81@163.com, b534667591@qq.com
}

Keywords: Applied undergraduate, General education curriculum, Wuhan dialect.

\begin{abstract}
In order to cultivate the applied talents to adapt to the development of regional economy and let the students know more about the dialect and culture of Wuhan, on the basis of the previous investigation, the subject group has established the general course of "Wuhan dialect and culture" in Wuhan Business College. And combined with the students' feedback to the course, some strategies are put forward for solving problems in the teaching practice of the course.
\end{abstract}

\section{Introduction}

With the need of transformation and development of newly established universities, the teaching contents and methods of the language courses are hard to adapt to the actual needs of today's society. Since Wuhan launched the so-called "most relaxed policy in history" in 2014, more and more graduates who were not native were willing to work in Wuhan. However, because of the misunderstanding of Wuhan culture and dialect, it is difficult for such college students to have a sense of belonging to the city. All in all, improving the level of Wuhan dialect and adapting to the needs of local industry and economy is a realistic problem to be solved for the applied talents in application-oriented universities.

The curriculum is the key to cultivate the talents. In response to the implementation of the project of "millions of undergraduate students staying in Wuhan", the course of "Wuhan dialect and culture" is established in Wuhan Business University. The purpose of this course is to make college students pay attention to Wuhan dialect and culture through learning the Wuhan dialect, inheriting the Wuhan culture and protect the martial arts. Also, in the process of learning, the university students can be familiar with Wuhan dialect and culture as soon as possible, and improve their comprehensive quality, even fall in love with Wuhan. Thus, they could adapt to the life of Wuhan after graduation much better. Meanwhile, the practice teaching of Wuhan dialect is a significant part of the local applied undergraduate course, which has a very crucial influence on the enhancement of students' awareness of innovation, the ability to innovate, and the improvement of the relevant professional attainment of the students

\section{The Purpose of the Course}

The training of Applied Talents in local colleges and universities is an important measure of the strategic adjustment of national talent training in recent years, and also it is an effective means for the economic and social development of local undergraduate colleges and universities. After the release of The Outline of the National Medium and Long-Term Education Reform and Development Plan (2010-2020), many experts and scholars in China have carried out deep and extensive research on the training mode of applied talents, and the results are plentiful. On the basis of absorbing the achievements of predecessors, we have identified the objectives of Wuhan dialect and culture through investigation and study [1].

Firstly, the course helps students to understand the zoning and the history of development of Chinese dialects. Student can also master the four functions of a dialect: the tool of communication, the carrier of culture, the bond of emotion, and the house of the homesickness.

Secondly, the course promotes the improvement of students' humanistic quality. Learning from the local related language and culture will help the students from all over the world to further 
comprehend the local culture, understand the traditional festivals, local characteristics and local culture in Wuhan, improve the level of dialects understanding and communication, and realize the overall development of the body and mind.

Thirdly, the course cultivates the students' fondness for Wuhan culture. It helps they actively absorb the nutrition of local culture in their study, work and life in Wuhan, and they will gradually form the spiritual attitude of "dare to be the first and pursue excellence" in the process of local cultural identity.

Fourthly, it is beneficial to the protection of dialects. Setting up dialects and culture courses in college students can cultivate students' sense of cultural protection and let them consciously regard dialects as objects of inheritance.

\section{The Evaluation and Analysis of the Course}

The teaching of dialect and culture should pay close attention to the diachronic development and dynamic evolution of dialect culture. [2] It enables learners to understand the essence of Wuhan's history in the learning of dialect culture. In this article, we got the feedback from 109 students who have selected the course of "Wuhan dialect and culture" in Wuhan Business University. This paper analyses from four aspects, the satisfaction degree of the course, the learning attitude of Wuhan dialect, the learning harvest and the learning needs of the subject. The statistical analysis as follows:

Firstly, in the course of satisfaction, about $93 \%$ of the students are interested in the course, the learning effect is very obvious, and it proves to win a better response. From the experience of the students' feedback, we can see that $95 \%$ of the students feel better in the classroom. This phenomenon fully shows that more and more college students begin to understand the culture of Wuhan dialect, and more and more love and attach importance to it. In the face of this phenomenon, we should strengthen the inheritance and make the dialect culture that represents the historical characteristics of the dialect.

Secondly, results about the learning attitude of the course. Because of the newly established dialectal culture courses, most students have strong learning desire for courses. About $91 \%$ of the students are more active in the classroom and are willing to make their own opinions in class. Most of the students deem that the "Wuhan dialect culture" course has benefited a lot. 99\% of students will voluntarily recommend this course to other students. This phenomenon shows that the curriculum has gained a high degree of recognition.

Thirdly, in aspect of learning and harvesting from the course, 59\% of the students deemed the curriculum enriched their understanding of Wuhan dialect and history, and will have a positive impact on the survival and the development of Wuhan in the future. About $87 \%$ of students are willing to read books related to Wuhan dialect after the class, so that they can learn by themselves. This shows that most students understand Wuhan dialect deeply, and begin to pay attention to Wuhan dialect.

Fourthly, in the aspect of the learning needs of the curriculum, as the teaching content is mainly based on the theoretical knowledge of Wuhan dialect culture, and the class is lack of interest and practical. Students generally expect that more interaction, let students more participate in the classroom to express their ideas, to share the dialect of their hometown and Wuhan dialect differences. Also, majority of them hope diverse curriculum forms, involving video sharing, speech, Wuhan dialect drama, sub group practice. Students with high degree of satisfaction are concentrated in Wuhan food (89\%), Wuhan landscape (66\%), Wuhan dialect (50\%), Wuhan folk custom (48\%), Wuhan history (47\%), etc.

\section{The Strategy of Curriculum Improvement}

In the process of dialect teaching, we are supposed to adhere to the principle of "student as the main body", so that students can acquire more knowledge and enhance their dialect ability and emotional experience. Stufflebeam says "The most important purpose of the evaluation is not to prove, but to improve” [3]. The students' evaluation reflects the teaching effect of the teachers. After the statistical 
analysis of the early teaching feedback, we make a few adjustments to the teaching method, mainly from the aspects of students' learning and development, the setting of the course content, the link between teachers and students, the practice of the course content, the composition of students' achievements and so on. The details are as follows:

Firstly, according to the feedback from students, the new teaching course is divided into two parts: "spoken language" and "theory". Speaking, that is to say, teach students to learn 10 classical Wuhan dialects before the beginning of each class, and increase the teaching link of real time spoken language. The theory is to enhance the understanding and learning of Wuhan dialect's regional, cultural and historical knowledge. Through the combination of theory and practice, on the one hand, enrich the theoretical knowledge of students, on the other hand, to learn Wuhan dialect in class, improve students' interest in learning, pay attention to the main role of students, and strengthen the students' sense of practice participation.

Secondly, after each course, we check students' learning effect through homework arranged, and mobilize the enthusiasm of students to study independently after class. The arrangement contents that making friend with a Wuhan friend to understand the historical events of Wuhan, Wuhan snack, Wuhan opera and the sightseeing of the humanistic landscape of Wuhan and so on. The content is comprehensive, so that the students will have greater space to encourage the students to go out and experience the culture of Wuhan dialect, feel their charm, and then explore their own learning independently. Finally, let students share their experience with PPT or form an experiment report. For course assessment and performance evaluation, oral English accounted for 30\%, final report sharing accounted for $40 \%$, and usual course participation accounted for $30 \%$.

Thirdly, the course should enrich practice activities inside and outside class, and create characteristic culture experience atmosphere. The practice of the curriculum includes the oral practice of Wuhan dialect, the topic discussion of the curriculum. Diverse forms of the curriculum assure the students richly participate and enjoy in it. The course selects some classical Wuhan dialect as oral practice material which votes by Wuhan dialect expert Zhu Jianhua, Wuhan art master He Zuohuan, Chinese cultural heritage protection of the annual outstanding figure, "Wuhan Tong" Liu Qianding and the majority of Wuhan netizens. In the extracurricular practice, students would try to communicate in Wuhan dialect; what's more, through reading a novel about Wuhan, seeing a Wuhan dialect film, listening to a Chu opera and so on, they would experience the Wuhan dialect and culture.

\section{Acknowledgement}

This research was financially supported by the Wuhan Teaching Research Foundation (2017095) \& Wuhan Business University Teaching Research Foundation (2016Y003).

\section{References}

[1] Chong Guo, Yuqin Xiao, A Survey of Local Dialect Use among College \& University Students in Wuhan, Journal of Wuhan Business University. 31(2018) 73-76.

[2] Zhenhe Zhou, Rujie You, The Dialect and Chinese Culture, Shanghai People's Publishing House, Shanghai, 2006:47.

[3] D.L.Stufflebeam, A.G. Shinkfield, EvaIuation Theory, Models, and Applications, Jossey Bass, 2007 